\title{
Off-Label Application of Pipeline Embolization Device for Intracranial Aneurysms
}

\author{
Buqing Liang, $\mathrm{MD}^{1,2}$, Walter S. Lesley, MD, MBA, CPE, FACR ${ }^{1,2}$, Timothy M. Robinson, $\mathrm{MD}^{1,2}$, \\ Wencong Chen, $\mathrm{PhD}^{3}$, Ethan A. Benardete, $\mathrm{MD}, \mathrm{PhD}^{1,2}$, Jason H. Huang, MD, FAANS, FACS ${ }^{1,2}$ \\ ${ }^{1}$ Department of Neurosurgery, Baylor Scott \& White Health, Temple, TX, USA \\ ${ }^{2}$ Texas A\&M University HSC-COM, Temple, TX, USA \\ ${ }^{3}$ Department of Biostatistics, Baylor Scott \& White Research Institute, Temple, TX, USA
}

Purpose: The Pipeline embolization device (PED) is approved in the USA for treating giant and large aneurysms arising from the petrous to superior hypophyseal segments of the internal carotid artery in patients older than 21 years of age. This study investigates off-label PED results in a large cohort.

Materials and Methods: Retrospective, single-center review of all patients who had off-label PED surgery.

Results: Sixty-two aneurysms (48 patients) underwent off-label PED treatment from 20122017. There were 44 females and four males (age 21 to 75 years; mean/median, 54.3/55.0 years). The most common presenting symptom was headache $(47 / 62,75.8 \%)$. All aneurysms were in the anterior circulation. Aneurysm size ranged from 1.4 to $25.0 \mathrm{~mm}$ (mean/median, 7.6/6.9 $\mathrm{mm}$ ). Fifty-two aneurysms had post-operative imaging with total/near-complete occlusion of 84.6\% (44/52). Aneurysm-based operative near-term complication rate was $9.7 \%$ while there were no permanent complications. For aneurysms and headache, $86.7 \%$ improved/resolved after embo-surgery, and were four times more likely to have a better clinical outcome (resolved or improved symptoms) after surgery (odds ratio [OR], 4.333; $\mathrm{P}=0.0325$ ). Left-sided aneurysms had a higher occlusion rate $(\mathrm{OR}, 20 ; \mathrm{P}=0.0073)$. Hypertension $(\mathrm{OR}, 4.2 ; \mathrm{P}=0.0332)$ and smoking $(\mathrm{OR}, 7 ; \mathrm{P}=0.0155)$ were more prone towards aneurysm occlusion. Patients without a family history were 14 times more likely to have favorable imaging outcome ( $P=0.0405)$. There is no difference of occlusion rates between untreated and previously treated aneurysms ( $P=0.6894)$. Overall, occlusion rate decreased by $14 \%$ with an increase of aneurysm size by $1 \mathrm{~mm}(\mathrm{P}=0.0283)$. Conclusion: For anterior circulation aneurysms, the off-label application of PED is as effective and safe as reported for on-label intracranial aneurysms.

Key Words: Pipeline embolization device; Intracranial aneurysm

\author{
Correspondence to: \\ Buqing Liang, MD \\ Department of Neurosurgery, Baylor \\ Scott \& White Health, 2401 S 31st St., \\ Temple, TX 76508, USA \\ Tel: $+1-254-724-5788$ \\ Fax: +1-254-724-5779 \\ E-mail: buqing@buqing.org \\ Received: March 17, 2019 \\ Revised: May 22, 2019 \\ Accepted: June 3, 2019
}

\begin{abstract}
Copyright $\odot 2019$ Korean Society of Interventional Neuroradiology This is an Open Access article distributed under the terms of the Creative Commons Attribution Non-Commercial License (http://creativecommons.org/licenses/by-nc/3.0) which permits unrestricted non-commercial use, distribution, and reproduction in any medium, provided the original work is properly cited.
\end{abstract}




\section{INTRODUCTION}

In 2011, the U.S. Food and Drug Administration approved Pipeline embolization device (PED) as the single flow divertor $^{1}$ for the use of treatment in large or giant wide-necked internal carotid artery aneurysms from the petrous to the superior hypophyseal segments in patients who are 22 years of age or older. ${ }^{2}$ Ever since, the application of PED has been explored in multiple off-label scenarios. ${ }^{3}$ However, the value of PED in treating aneurysms outside of the aforementioned criteria such as those that are $<10 \mathrm{~mm}$ in diameter, distal to superior hypophyseal artery, fusiform/tandem/blood blister-like in shape, previously ruptured/treated, etc., remains unclear. Our study aims to elucidate the off-label role PED plays in treating these aneurysms.

\section{MATERIALS AND METHODS}

This study is a single-institute retrospective study investigating patients who underwent off-label PED treatment between January 1, 2012 and December 30, 2017. The study was Institutional Review Board (IRB) of Baylor Scott \& White Health approved and consent was waived due to the retrospective, observational nature of the study (IRB 017292).

\section{Inclusion criteria}

On-label PED indications are: age $\geq 22$ years; size $\geq 10 \mathrm{~mm}$; neck $\geq 4 \mathrm{~mm}$ or dome/neck $<2$; aneurysm location from petrous to superior hypophyseal internal carotid artery. Treated aneurysms that did not fit these criteria were considered as off-label and were enrolled. Typical examples included: aneurysm size $<10 \mathrm{~mm}$; previously ruptured aneurysms with recurrence that were coiled/stented or clipped; tandem/blood blister-like/fusiform aneurysms; aneurysms distal to superior hypophyseal artery.

\section{Peri-operative anti-platelet management}

All elective cases were treated with dual anti-platelet therapy (DAPT) before the deployment of PED with either aspirin (81 mg daily or $325 \mathrm{mg}$ daily) and clopidogrel (75 mg daily), or aspirin (81 mg daily or $325 \mathrm{mg}$ daily) and ticagrelor $(90 \mathrm{mg}$ twice a day, used for clopidogrel hypo- or non-responders) for 7-10 days prior to procedure. For emergent cases, a loading dose of aspirin $(650 \mathrm{mg}$ ) and clopidogrel $(375 \mathrm{mg}$ ) was used. P2Y12 platelet response tests for clopidogrel and aspi- rin were not routinely obtained as this lab analysis regimen varied both among surgeons and even varied with individual surgeon during the study period. However, for clopidogrel non-responders, ticagrelor was utilized. There was one case where eptifibatide drip was administered intra-operatively. For all patients, aspirin was maintained up to 1 year, while the other anti-platelet medication was continued for at least 3 to 6 months.

\section{Follow-up assessment}

The endpoint was either radiographic evidence of occlusion or patient's last clinical assessment. Computed tomography angiography (CTA), magnetic resonance angiography (MRA), and digital subtraction angiography (DSA) were used for the evaluation of occlusion. The results were classified as complete occlusion (100\%), near-complete occlusion (90-100\%), incomplete occlusion (<90\%), or no effect (0\%). Routine screening in asymptomatic patients for complications such as ischemic/hemorrhagic strokes was not performed. Clinical notes by either Neurosurgery or other specialties such as Neurology, Family Medicine, were checked for baseline and post-operative, aneurysm-related symptoms. Clinical outcomes were classified as 1) improved/resolved, 2) persistent/ unchanged, 3) asymptomatic both pre- and post-PED, and 4) new symptoms.

\section{Statistical analysis}

Univariate logistic regression models were implemented to select the possible predictors. A P-value of less than 0.2 was included as possible predictors in the final model. A multivariate logistic regression model was fit to the data. The Hosmer-Lemeshow test was used to assess fitness of data. Candidate predictors were variables that had P-values of 0.2 or less. These variables were: headache, side, smoking, family history, and size. All of the potential predictors were included in the final model. The forward and backward model selection procedures were used to find the potential predictors. Therefore, the binary clinical outcome (improved and resolved versus other clinical outcomes) and image results were evaluated by multivariate logistic regression, adjusted for side, smoking, family history, and size. All the P-values were reported. The c-statistics were equal to 0.86 and 0.77 for clinical outcome and image results separately, indicating that the models predict about $86 \%$ and $77 \%$ of the variability in the model. The Hosmer-Lemeshow test indicates a good fit to the data. A P-value of less than 0.05 was considered as 
Table 1. Patient/aneurysm/treatment/outcome characteristics

\begin{tabular}{|c|c|}
\hline & Value \\
\hline Patients/aneurysms & $48 / 62$ \\
\hline \multicolumn{2}{|l|}{ Gender } \\
\hline Male/female & $4(6.45) / 44(93.55)$ \\
\hline \multicolumn{2}{|l|}{ Age (years) } \\
\hline Range & $21-75$ \\
\hline Mean/median & $54.3 / 55.0$ \\
\hline \multicolumn{2}{|l|}{ Presenting symptoms } \\
\hline Headache & $47(75.8)$ \\
\hline Asymptomatic & $10(16.1)$ \\
\hline Vision changes & $9(14.5)$ \\
\hline Dizziness/vertigo & $7(11.3)$ \\
\hline Cranial nerve III deficits & $5(8.1)$ \\
\hline Tinnitus & $5(8.1)$ \\
\hline Nausea/vomiting & $3(4.8)$ \\
\hline Dysphasia & $1(1.6)$ \\
\hline Smoking & $46(74.2)$ \\
\hline Hypertension & $41(66.1)$ \\
\hline Diabetes mellitus & $4(6.45)$ \\
\hline Family history & $5(8.1)$ \\
\hline \multicolumn{2}{|l|}{ Aneurysm size (mm) } \\
\hline Range & $1.40-25.0$ \\
\hline Mean/median & $7.6 / 6.9$ \\
\hline \multicolumn{2}{|l|}{ Aneurysm neck size (mm) } \\
\hline Range & $1.2-12$ \\
\hline Mean/median & $4.2 / 3.85$ \\
\hline
\end{tabular}

Side

Left/right

$32(51.6) / 30(48.4)$

\begin{tabular}{lc} 
Aneurysm locations & \\
Ophthalmic & $12(19.35)$ \\
Posterior communicating & $12(19.35)$ \\
Supra-clinoid & $11(17.7)$ \\
Superior hypophyseal & $8(12.9)$ \\
Cavernous & $6(9.7)$ \\
Para-clinoid & $6(9.7)$ \\
Dural ring & $6(9.7)$ \\
MCA segment 1 & $1(1.6)$ \\
Ruptured & $14(22.6)$ \\
Prior treatment & $20(32.3)$ \\
Coiled & $12(19.4)$ \\
Stented & $2(3.2)$ \\
Coiled and stented & $2(3.2)$ \\
Coiled, stented, and clipped & $2(3.2)$ \\
Clipped & $1(1.6)$ \\
Coiled and clipped & $1(1.6)$ \\
\hline
\end{tabular}

Table 1. Continued

\begin{tabular}{lc}
\hline & Value \\
\hline Morphology & \\
Saccular & $46(74.2)$ \\
Lobulated & $8(12.9)$ \\
Blood blister-like & $3(4.8)$ \\
Tandem & $3(4.8)$ \\
Fusiform & $2(3.2)$ \\
Treatment & \\
PED only & $60(96.8)$ \\
PED with coiling & $2(3.2)$ \\
\hline
\end{tabular}

Values are presented as number (\%) or range.

MCA, middle cerebral artery; PED, Pipeline embolization device.

significant. All statistical analysis was performed in SAS 9.4 (SAS Institute Inc., Cary, NC, USA).

\section{RESULTS}

A total of 62 aneurysms underwent off-label PED treatment during the study period, and these were enrolled for data analysis (Table 1). A total of 54 procedures were performed. All of these aneurysms were treated by surgeons: W.L. (48), E.B. (6), and others (8).

\section{Demographic characteristics}

The 62 aneurysms afflicted 48 total patients (44 females and four males). Age range was 21 to 75 years of age with a mean age of 54.3 years and median of 55.0 years. Forty-one aneurysms were in Caucasian patients, eleven in African descent patients, six in Hispanic patients, three in Asian patients, and one in a Puerto Rican patient. The most common presenting symptom was headache (47/62, 75.8\%). Other symptoms included cranial nerve-III deficits (5, 8.1\%), vision changes (9, $14.5 \%)$, dizziness/vertigo (7, 11.3\%), tinnitus (5, 8.1\%), nausea/ vomiting (3, 4.8\%), and dysphasia (1, 1.6\%). Ten aneurysms were discovered in asymptomatic patients. The most common co-morbidities included hypertension (41, 66.1\%) and diabetes mellitus (4, 6.45\%). Five (8.1\%) aneurysms were in patients with a family history of cerebral aneurysm, and 46 (74.2\%) aneurysms were in patients with a positive smoking history.

\section{Aneurysm characteristics}

The size of the aneurysms ranged from $1.4 \mathrm{~mm}$ to $25.0 \mathrm{~mm}$, 
with a mean of $7.6 \mathrm{~mm}$ and median of $6.9 \mathrm{~mm}$. The neck size ranged from $1.2 \mathrm{~mm}$ to $12 \mathrm{~mm}$ with a mean of $4.2 \mathrm{~mm}$ and a median of $3.9 \mathrm{~mm}$. Forty-five (72.6\%) aneurysms were small aneurysms (largest diameter $<10 \mathrm{~mm}$ ). Thirty-two (51.6\%) aneurysms were on the left side and 30 (48.4\%) aneurysms were on the right side. The specific locations of the aneurysms were distributed as following: ophthalmic (12, $19.4 \%)$, posterior communicating (12, 19.4\%), supra-clinoid (11, $17.7 \%)$, superior hypophyseal $(8,12.9 \%)$, cavernous $(6,9.7 \%)$, para-clinoid (6, 9.7\%), dural ring (6, 9.7\%), and M1 (1, 1.6\%). The shapes of the aneurysms were classified into the following five groups: saccular (46, 74.2\%), lobulated (8, 12.9\%), tandem (3, 4.8\%), blood blister-like aneurysm (3, 4.8\%), and fusiform $(2,3.2 \%)$. Fourteen aneurysms were ruptured (22.6\%). Due to the multiple treatment combinations, pre-PED interventions were comprised of nineteen (30.7\%) endovascular and four (6.45\%) open surgeries in twenty aneurysms (32.3\%): twelve (19.4\%) underwent coiling only; two (3.2\%) underwent stenting only; two (3.2\%) underwent coiling and stenting; two (3.2\%) underwent coiling, stenting, and clipping; one (1.6\%) underwent clipping only; one (1.6\%) underwent both coiling and clipping.

\section{Treatment and post-operative course}

Pre-operatively, all aneurysms received aspirin therapy. Sixty-one (98.4\%) aneurysms received clopidogrel, two non-responders and the remaining one received ticagrelor (4.8\%). Sixty (96.8\%) aneurysms were treated by PED only and two (3.2\%) aneurysms were treated with PED and coiling. Post-operatively, all aneurysms continued with aspirin. All but four aneurysms were managed with aspirin and clopidogrel regimen. In the four (6.5\%) that received variation of DAPT, three were treated with ticagrelor, while the fourth an- eurysm developed intra-operative PED platelet aggregation prompting eptifibatide drip which was later switched to oral aspirin and clopidogrel therapy. All aneurysms were treated with a single PED. Two (3.2\%) aneurysms received adjunctive coil embolization. Out of the 14 ruptured aneurysms, only one received emergent PED on post-bleeding day (PBD) 3 which appeared to be blood-blister like on DSA on PBD 1. She was loaded with $650 \mathrm{mg}$ Aspirin and $180 \mathrm{mg}$ Ticagrelor (Clopidogrel non-responder) on the day before the PED embolization. All other 13 were treated as an elective case based on follow-up imaging indicating non-occlusion (ranges from 1 month to 100 months; mean, 24 months; median, 10 months). Aneurysm-based complication rate was 9.7\% (6/62), including one patient who had two aneurysms (Table 2). When calculated as procedure-based, the complication rate dropped slightly to 9.3\% (5/54). However, all patients' complications quickly resolved, and they were discharged without permanent neurological deficit. The length of stay ranged from 1 night (48,77.4\%), 2 nights (10, 16.1\%), 3 nights (2, 3.2\%), 5 nights (1, 1.6\%), and 21 nights (1, 1.6\%). The prolonged 21 nights stay was for a patient presenting with a ruptured blood blister aneurysm.

\section{Follow-up}

Fifty-two (83.9\%) aneurysms had post-operative imaging at an average follow-up of 327 days and a median of 358 days. Most aneurysms received initial radiographic evaluation between 6 months and 1 year post-operatively. MRA was the most commonly used method for 31 aneurysms (59.6\%), while DSA was obtained for 17 aneurysms (32.7\%) and CTA was utilized in four aneurysms (7.7\%). Among the four aneurysms followed with CTA, three aneurysms were in one patient with triplet tandem aneurysms.

Table 2. Case-based complications and consequences

\begin{tabular}{|c|c|}
\hline Complication (aneurysms involved) & Follow up \\
\hline Cutaneous bleeding from neuromonitoring needle sites (1) & Required red blood cell transfusion, resolved \\
\hline Facial droop and arm weakness (1) & Resolved without intervention \\
\hline MCA territory ischemic stroke (1) & No long-term neurologic deficits \\
\hline PED with vessel occlusion $(1)^{*}$ & Asymptomatic \\
\hline Sub-arachnoid hemorrhage $(2)^{\dagger}$ & No neurologic deficit \\
\hline
\end{tabular}


The total/near-complete occlusion rate was 84.6\% (44/52); partial occlusion was achieved in seven aneurysms (13.5\%); and only one aneurysm (1.9\%) had no response to PED (Table 3). As seen from Tables 4 and 5, aneurysms on the left side had a higher occlusion rate (odds ratio [OR], 20; $\mathrm{P}=0.0073$ ). Aneurysms in patients with a history of hypertension (OR, 4.2; $\mathrm{P}=0.0332)$, smoking $(\mathrm{OR}, 7 ; \mathrm{P}=0.0155)$, and without a family history $(O R, 14 ; P=0.0405)$ were more likely to respond to PED, separately. With an increase of aneurysm size by $1 \mathrm{~mm}$, the occlusion rate on follow-up imaging decreased by $14 \%$ $(\mathrm{P}=0.0283)$. As for the 20 aneurysms previously treated with either coiling or clipping or both, 16 have follow-up imaging with an occlusion rate of $81.25 \%$ (13/16). Out of the remaining 42 previously untreated aneurysms, 31 out of the 36 that has

\section{Table 3. Radiographic and clinical outcome}

\begin{tabular}{lc}
\hline & Value \\
\hline Aneurysm-based radiographic outcome & 52 \\
Total/near-complete occlusion & $44(84.6)$ \\
Partial occlusion & $7(13.5)$ \\
No effect & $1(1.9)$ \\
Aneurysm-based clinical outcome at last follow-up & 60 \\
Improved/resolved & $39(65)$ \\
Persistent/unchanged & $7(11.7)$ \\
Asymptomatic pre- and post-PED & $4(6.7)$ \\
New headache & $1(1.7)$ \\
\hline
\end{tabular}

Values are presented as number (\%).

PED, Pipeline embolization device.

Table 4. Univariate and multivariate logistic regression for the clinical outcome with adjusted variables*

\begin{tabular}{lccc}
\hline Variable & OR & $95 \% \mathrm{Cl}$ & P-value $^{\dagger}$ \\
\hline Univariate analysis & & & \\
$\quad$ Headache & 4.33 & $1.124,17.217$ & $\mathbf{0 . 0 3 2 5}$ \\
Side & 0.05 & $0.003,0.289$ & $\mathbf{0 . 0 0 5 8}$ \\
Hypotension & 4.20 & $1.138,16.692$ & $\mathbf{0 . 0 3 3 2}$ \\
$\quad$ Smoking & 7.00 & $1.812,29.6$ & $\mathbf{0 . 0 0 5 6}$ \\
Multivariate analysis & & & \\
$\quad$ Side & 0.05 & $0.005,0.438$ & $\mathbf{0 . 0 0 7 3}$ \\
$\quad$ Smoking & 7.61 & $1.483,39.038$ & $\mathbf{0 . 0 1 5 0}$ \\
\hline
\end{tabular}

OR, odds ratio; $\mathrm{Cl}$, confidence interval.

${ }^{*}$ Clinical outcome is defined as binary data, if resolved or improved, the clinical outcome will be counted as 1; otherwise, it is 0 .

${ }^{\dagger}$ If $\mathrm{P}$-value $<0.05$, the font is bolded. follow-up imaging achieved total occlusion, resulting a rate of $86.11 \%$. There is no statistical difference for the occlusion rate between two groups $(\mathrm{P}=0.6894)$.

Sixty (96.8\%) aneurysms had clinical follow up with an average of 383 days and a median of 367 days. Among them, 48 (80.0\%) aneurysm-associated symptoms improved/ resolved, seven (11.7\%) persisted, four (6.7\%) asymptomatic aneurysms remained so both pre- and post-PED, and one (1.7\%) had new symptom of headache (Table 3). For 45 (72.6\%) aneurysms with pre-PED headache, $39 \mathrm{improved} / \mathrm{res}$ olved (39/43, 90.7\%; two missing follow-up). Overall for aneurysms with associated headaches, following PED treatment, these aneurysms had a four-fold increased likelihood for improved/ resolved headaches $(\mathrm{OR}, 4.333$; $\mathrm{P}=0.0325$ by univariate analysis; not significant by multivariate analysis).

\section{DISCUSSION}

\section{Gender distribution}

In our study, the female to male ratio of 11.4:1 is dramatically skewed from the known aneurysm prevalence of 3:2 distribution. However, similar demographics were also reported in other studies. ${ }^{4,5}$ Becske et al. ${ }^{4}$ attribute the bias to two factors: 1) gender predilection for the cavernous internal carotid artery $^{6}$ and 2) referral bias. Other contributing factors that may explain these results include: 1) females seem to have an increased risk of formation and growth of intracranial aneurysms $^{7-9}$ and 2) women more frequently seek medical attention than men. ${ }^{10}$

Table 5. Univariate and multivariate logistic regression for the image results with categorical and continuous variables*

\begin{tabular}{lccc}
\hline Variable & OR & $95 \% \mathrm{Cl}$ & P-value $^{\dagger}$ \\
\hline Univariate analysis & & & \\
Size & 0.897 & $0.789,1.011$ & 0.071 \\
Neck & 0.816 & $0.629,1.058$ & 0.1124 \\
Family history & 0.07 & $0.003,0.832$ & $\mathbf{0 . 0 4 0 5}$ \\
Multivariate analysis & & & \\
Family history & 0.035 & $0.002,0.528$ & $\mathbf{0 . 0 1 5 5}$ \\
Size & 0.864 & $0.759,0.985$ & $\mathbf{0 . 0 2 8 3}$ \\
\hline
\end{tabular}

$\mathrm{OR}$, odds ratio; $\mathrm{Cl}$, confidence interval.

*The image result is defined as binary data. If the image shows complete occlusion, it will be counted as 1, otherwise, it is 0 .

${ }^{\dagger}$ If P-value $<0.05$, the font is bolded. 


\section{Headache and treatment}

Headache is a common presentation of unruptured intracranial aneurysms, with a reported rate of 18-34\%." Studies have pointed out that the structural change of the artery that disturbs the innervating nerve could be the mechanism, and that treatment of the aneurysm can be effective in improving the symptoms. ${ }^{12,13}$ Kong et al. ${ }^{14}$ reported that after clipping or coiling treatment of aneurysms, $89.8 \%$ patients' headaches improved. Our study corroborates this favorable outcome in patients with headaches who undergo PEDbased aneurysm surgery. On the other hand, endovascular aneurysm surgery may rarely cause de novo headaches. In our study, there was just one patient with new headache after treatment, accounting for only $1.6 \%$ of total aneurysms treated. Others have reported similar low incidence of new post-operative headache, but when it occurs, it tends to resolve over time. ${ }^{15}$

\section{Smoking}

Our data reveals that patients with a smoking history have a better occlusion rate $(O R, 7 ; P<0.05)$. Similarly, both Adeeb et al. ${ }^{16}$ and Griessenauer et al. ${ }^{5}$ found that smoking status had a significantly favorable relationship with the occlusion of the aneurysms. However, by stratifying 694 aneurysms treated with PED into never, current, former smoker groups, Rouchaud et al. ${ }^{17}$ could not conclude that smoking affected occlusion rates. Given that smoking has long been identified as a risk factor for the formation, growth, and rupture of intracranial aneurysms, ${ }^{7,8,18-20}$ further study of smoking history and PED occlusion response is warranted.

\section{Family history}

Patients with a family history of aneurysms had a lower occlusion rate to PED $(O R, 14 ; \mathrm{P}<0.05)$. We postulate that different mechanisms of formation and growth of aneurysms in patients with a family history may influence the in vivo response to PED. Studies have shown that inflammation plays an important role in the aneurysms formation and growth in smokers ${ }^{18}$ while familial aneurysms may be related to genetic disorders. ${ }^{21}$ Further research on these different responses to PED treatment of aneurysms is warranted.

\section{Outcomes of PED treated aneurysms}

The occlusion rate of aneurysms has been reported at various follow-up intervals and tends to increase as the follow-up time elongates. ${ }^{22}$ Though there is no consensus as to when the imaging follow-up should be performed; in general, 6 months to 1 year is commonly used. Various sources have reported an occlusion rate ranging from $75 \%$ to $95 \%{ }^{16,22-24}$ Our study has a mean/median follow-up of 327/358 days. The total/near-complete occlusion rate achieved $84.6 \%$. Our data indicates that off-label PED treatment is as effective as on-label application. Among the 45 small aneurysms, 37 (37/45, 82.2\%) had follow-up imaging, and 31 (31/37, 83.8\%) had complete occlusion, five (5/37, 13.5\%) had partial occlusion, only one (1/37, 2.7\%) remained no change. In another study of small aneurysms treated with PED, it was reported to have a complete occlusion rate of $72 \%$, and partial occlusion rate of $28 \%$ at a mean follow up of 6.3 months. ${ }^{25}$ Among the 14 ruptured aneurysms, 11 (11/14, 78.6\%) aneurysms had follow-up imaging, and 10 (10/11, 90.9\%) of them revealed complete occlusion, including the one treated emergently on PBD 3 , while only one $(1 / 11,9.1 \%)$ aneurysm remained no change at post-operative day (POD) 303. Chalouhi et al. ${ }^{26}$ reported a similar complete occlusion rate of $80 \%$ for ruptured aneurysms treated with PED. For aneurysms with previously failed coiling/clipping therapy, our occlusion rate reached 86.11\% after PED embolization which indicates that PED is an excellent backup/rescue option for these aneurysms. We included one case with three tandem aneurysms that were all occluded on POD 219 (Fig. 1). Awad et al. ${ }^{27}$ reported PED treatment for tandem aneurysms in seventeen patients with a mean final Raymond-Roy score of 1.3 \pm 0.7 . We had one unruptured, previously untreated $\mathrm{M} 1$ aneurysm that was found during the work-up of tinnitus in a 64-year-old female patient. On POD 406 of PED treatment, it regressed in size but was not occluded on the MRA study. Cagnazzo et al. ${ }^{28}$ performed a meta-analysis on middle cerebral artery aneurysms treated with PED and found a complete/near-complete occlusion rate of $78.7 \%$. A recent prospective multicenter trial of flow diversion for small and medium size aneurysms (PREMIER trial) ${ }^{29}$ evaluated 144 patients with intracranial aneurysms measuring less than $12 \mathrm{~mm}$, and $84.4 \%$ of which were less than $7 \mathrm{~mm} .^{30}$ Patient characteristics were similar with our study. A single PED was successful in treating $92.9 \%$ of all aneurysms. Rate of major stroke or death was $1.4 \%$ at 30 days and $2.1 \%$ at 1 year. Occlusion rate at 1 year was $83.5 \%$, similar to our results of $84.6 \%$. Although outcomes were similar, the PREMIER trial included aneurysms in the vertebral circulation up to the PICA, which our study only included aneurysms in the anterior circulation (internal carotid and middle cerebral artery). 

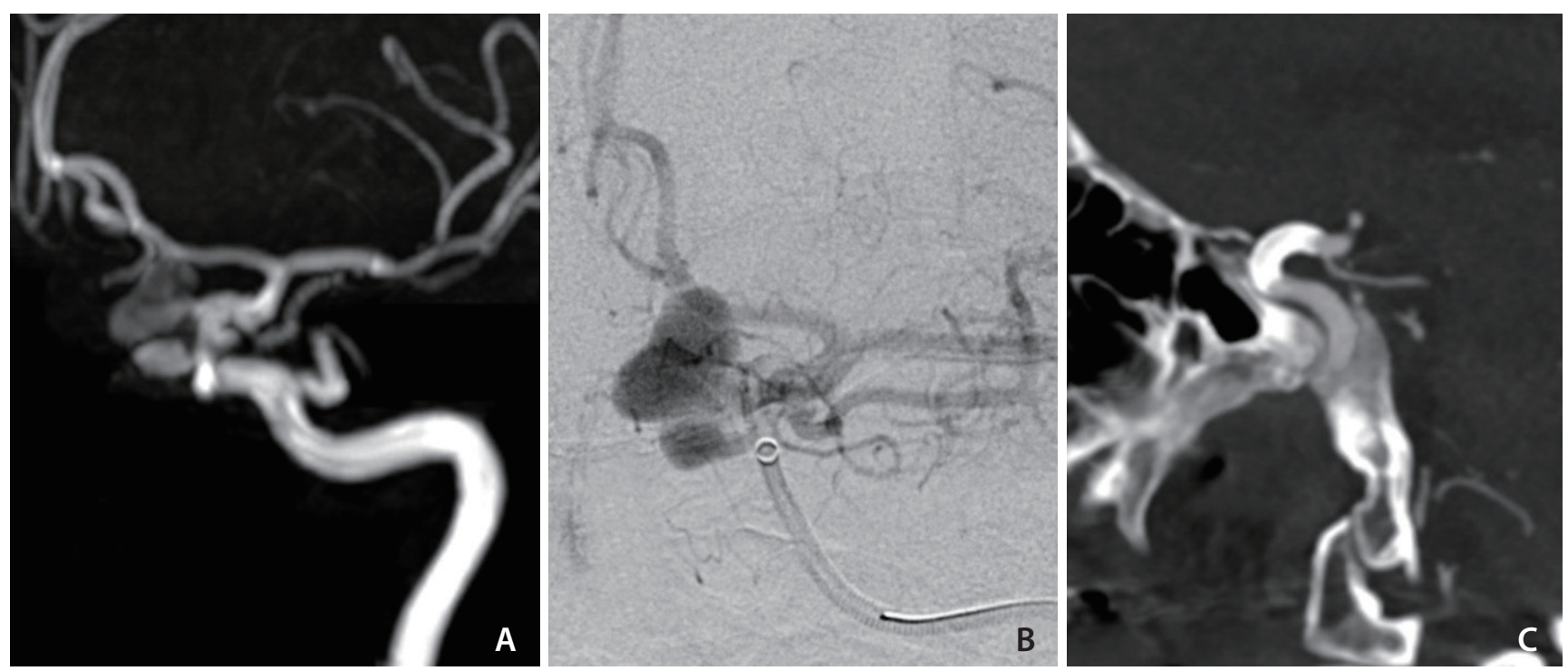

Fig. 1. (A) Three aneurysm cluster is seen on MRA imaging before the PED treatment. (B) Digital subtraction angiogram presentation of the triplet aneurysms. (C) Follow up sagittal CTA reveals that all three aneurysms are occluded (post-PED day 219). MRA, magnetic resonance angiography; PED, Pipeline embolization device; CTA, computed tomography angiography.

\section{Left-sidedness}

An interesting phenomenon observed in our study is that the aneurysms in the left anterior circulation had a better occlusion rate than those on the right side. Since PED promotes aneurysm regression in part by disruption of blood flow, a baseline difference in blood flow between the right and left carotid arteries might influence occlusion rates with PED. By using Doppler duplex scanner, Ackroyd et al. ${ }^{31}$ concluded that there was no significant difference of blood flow between the two carotid arteries in normal people. However, Urbanski et al. ${ }^{32}$ inspected the blood flow in the carotid arteries after cannulation and found that even though the flow rates were similar, the perfusion pressure was significantly higher in the left carotid than in the right carotid artery. In this study, higher occlusion rate was observed in both hypertension and in left-sidedness which seems to correlate with the phenomenon report by Urbanski et al. ${ }^{32}$ However, Schneiders et al. ${ }^{33}$ discovered that a flow diverter seems to have no effect on reducing the pressure in the aneurysm. As shown by previous studies, the mechanism of PED on aneurysms includes both stagnation of the blood flow in the aneurysm, which leads to thrombosis within the aneurysms, and endothelialization/neointima growth over the device strut at the aneurysm neck. ${ }^{34,35}$ It is unclear if higher perfusion pressure is related to either one of these mechanisms. ASPIRe ${ }^{23}$ study collected data on the sides of the aneurysms but did not mention any related occlusion difference. Several

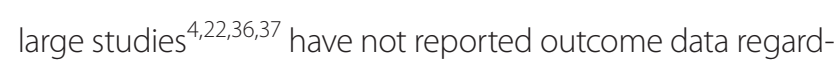
ing side of treated aneurysms. Nevertheless, the laterality of the aneurysm may be a weak or minor variable possibly impacting the flow dynamics of Pipeline flow diversion.

\section{Complications after treatment}

Aneurysm rupture, intraparenchymal hemorrhage, and ischemic strokes are the three most severe morbidities among patients treated with PED. ${ }^{23}$ The treatment-related morbidity rate has been reported to range from $4 \%$ to $10 \% .{ }^{28}$ In our study, aneurysm-based morbidity was $9.9 \%$, in which all events were short-term, and fully resolved by the time of discharge. In our study, there was no mortality. It is also worthwhile to mention that the patient with ruptured aneurysm loaded with DAPT before PED on PBD 3 recovered well with no new bleeding during the hospital course. This data indicates that off-label PED treatment is as safe as on-label applications.

\section{Limitations}

This study is limited by its nature of retrospective design. Due to the number of cases, we did not further subdivide these off-label cases into additional groups for analysis. While we do not have extended-term follow-up of PED cases (>2 years) to exclude recanalization following aneurysm occlusion, all studies to date do not indicate that recanalization occurs after Pipeline treatment. 


\section{CONCLUSION}

For anterior circulation aneurysms, the off-label application of PED is as effective and safe as reported for on-label intracranial aneurysms.

\section{Acknowledgments}

This study was presented in part at the 2018 American Association of Neurological Surgeons Annual Scientific Meeting in New Orleans, Louisiana, USA, April 28-May 2, 2018.

\section{REFERENCES}

1. Krishna C, Sonig A, Natarajan SK, Siddiqui AH. The expanding realm of endovascular neurosurgery: flow diversion for cerebral aneurysm management. Methodist Debakey Cardiovasc J 2014;10:214-219

2. US Food and Drug Administration. Instructions for Use (IFU) Pipeline Embolization Device. Silver Spring: US Food and Drug Administration; 2011

3. Patel PD, Chalouhi N, Atallah E, Tjoumakaris S, Hasan D, Zarzour $\mathrm{H}$, et al. Off-label uses of the Pipeline embolization device: a review of the literature. Neurosurg Focus 2017:42:E4

4. Becske T, Kallmes DF, Saatci I, McDougall CG, Szikora I, Lanzino G, et al. Pipeline for uncoilable or failed aneurysms: results from a multicenter clinical trial. Radiology 2013;267:858-868

5. Griessenauer CJ, Ogilvy CS, Foreman PM, Chua MH, Harrigan $M R$, He L, et al. Pipeline embolization device for small intracranial aneurysms: evaluation of safety and efficacy in a multicenter cohort. Neurosurgery 2017;80:579-587

6. Halbach W, Higashida RT, Dowd CF, Urwin RW, Balousek PA, Lempert TE, et al. Cavernous internal carotid artery aneurysms treated with electrolytically detachable coils. J Neuroophthalmol 1997;17:231-239

7. Juvela S, Poussa K, Porras M. Factors affecting formation and growth of intracranial aneurysms: a long-term follow-up study. Stroke 2001;32:485-491

8. Qureshi Al, Suarez Jl, Parekh PD, Sung G, Geocadin R, Bhardwaj A, et al. Risk factors for multiple intracranial aneurysms. Neurosurgery 1998;43:22-26; discussion 26-27

9. Ellamushi HE, Grieve JP, Jäger HR, Kitchen ND. Risk factors for the formation of multiple intracranial aneurysms. J Neurosurg 2001;94:728-732

10. Bertakis KD, Azari R, Helms L, Callahan EJ, Robbins JA. Gender differences in the utilization of health care services. J Fam Pract 2000:49:147-152

11. Arena JE, Hawkes MA, Farez MF, Pertierra L, Kohler AA, Marrodán $M$, et al. Headache and treatment of unruptured intracranial aneurysms. J Stroke Cerebrovasc Dis 2017;26:1098-1103

12. Schwedt TJ, Gereau RW, Frey K, Kharasch ED. Headache outcomes following treatment of unruptured intracranial aneurysms: a prospective analysis. Cephalalgia 2011;31:1082-1089

13. Schneider AM, Moore JM, Adeeb N, Gupta R, Griessenauer $\mathrm{CJ}$, Winkler PA, et al. Self-reported headaches in patients with unruptured intracranial aneurysms treated with the Pipeline embolization device. World Neurosurg 2018;113:e364-e372

14. Kong DS, Hong SC, Jung YJ, Kim JS. Improvement of chronic headache after treatment of unruptured intracranial aneurysms. Headache 2007;47:693-697

15. Khan S, Amin FM, Hauerberg J, Holtmannspötter M, Petersen JF, Fakhril-Din Z, et al. Post procedure headache in patients treated for neurovascular arteriovenous malformations and aneurysms using endovascular therapy. J Headache Pain 2016;17:73

16. Adeeb N, Moore JM, Wirtz M, Griessenauer CJ, Foreman PM, Shallwani $\mathrm{H}$, et al. Predictors of incomplete occlusion following Pipeline embolization of intracranial aneurysms: is it less effective in older patients? AJNR Am J Neuroradiol 2017;38:2295-2300

17. Rouchaud A, Brinjikji W, Cloft HJ, Lanzino G, Becske T, Kallmes DF. Smoking does not affect occlusion rates and morbidity-mortality after pipeline embolization for intracranial aneurysms. AJNR Am J Neuroradiol 2016;37:1122-1126

18. Chalouhi N, Ali MS, Starke RM, Jabbour PM, Tjoumakaris SI, Gonzalez LF, et al. Cigarette smoke and inflammation: role in cerebral aneurysm formation and rupture. Mediators Inflamm 2012;2012:271582

19. Can A, Castro VM, Ozdemir YH, Dagen S, Yu S, Dligach D, et al. Association of intracranial aneurysm rupture with smoking duration, intensity, and cessation. Neurology 2017;89:1408-1415

20. Juvela S, Porras M, Poussa K. Natural history of unruptured intracranial aneurysms: probability of and risk factors for aneurysm rupture. J Neurosurg 2000;93:379-387

21. Olson JM, Vongpunsawad S, Kuivaniemi H, Ronkainen A, Hernesniemi J, Ryynänen $M$, et al. Search for intracranial aneurysm susceptibility gene(s) using Finnish families. BMC Med Genet 2002;3:7

22. Saatci I, Yavuz K, Ozer C, Geyik S, Cekirge HS. Treatment of intracranial aneurysms using the Pipeline flow-diverter embolization device: a single-center experience with long-term follow-up results. AJNR Am J Neuroradio/ 2012;33:1436-1446

23. Kallmes DF, Brinjikji W, Boccardi E, Ciceri E, Diaz O, Tawk R, et al. 
Aneurysm Study of Pipeline in an Observational Registry (ASPIRe). Interv Neurol 2016;5:89-99

24. Brinjikji W, Murad MH, Lanzino G, Cloft HJ, Kallmes DF. Endovascular treatment of intracranial aneurysms with flow diverters: a meta-analysis. Stroke 2013;44:442-447

25. Chalouhi N, Zanaty M, Whiting A, Yang S, Tjoumakaris S, Hasan $D$, et al. Safety and efficacy of the Pipeline embolization device in 100 small intracranial aneurysms. J Neurosurg 2015;122:14981502

26. Chalouhi N, Zanaty M, Whiting A, Tjoumakaris S, Hasan D, Ajiboye N, et al. Treatment of ruptured intracranial aneurysms with the pipeline embolization device. Neurosurgery 2015;76:165172; discussion 172

27. Awad AW, Moon K, Yoon N, Mazur MD, Kalani MYS, Taussky P, et al. Flow diversion of tandem cerebral aneurysms: a multi-institutional retrospective study. Neurosurg Focus 2017;42:E10

28. Cagnazzo F, Mantilla D, Lefevre PH, Dargazanli C, Gascou G, Costalat $\mathrm{V}$. Treatment of middle cerebral artery aneurysms with flow-diverter stents: a systematic review and meta-analysis. AJNR Am J Neuroradio/ 2017;38:2289-2294

29. Prospective Study on Embolization of Intracranial Aneurysms With Pipeline ${ }^{\mathrm{TM}}$ Embolization Device (PREMIER). https://clinicaltrials.gov/ct2/show/NCT02186561. Accessed September 28, 2018

30. American Heart Association. Prospective, Multi-Center Study of Flow Diversion for Small and Medium-Sized Aneurysms: Results of the Premier Trial. https://professional.heart.org/idc/groups/ ahamah-public/@wcm/@sop/@scon/documents/downloadable/ucm_492111.pdf. Accessed October 1, 2018

31. Ackroyd N, Gill R, Griffiths K, Kossoff G, Appleberg M. Quantitative common carotid artery blood flow: prediction of internal carotid artery stenosis. J Vasc Surg 1986;3:846-853

32. Urbanski $P$, Lenos $A$, Lindemann $Y$, Zacher M, Frank S, Diegeler A. Use of a carotid artery for arterial cannulation: side-related differences. Thorac Cardiovasc Surg 2010;58:276-279

33. Schneiders JJ, VanBavel E, Majoie CB, Ferns SP, van den Berg R. A flow-diverting stent is not a pressure-diverting stent. AJNR Am J Neuroradiol 2013;34:E1-E4

34. Kadirvel R, Ding YH, Dai D, Rezek I, Lewis DA, Kallmes DF. Cellular mechanisms of aneurysm occlusion after treatment with a flow diverter. Radiology 2014;270:394-399

35. Kallmes DF, Ding YH, Dai D, Kadirvel R, Lewis DA, Cloft HJ. A new endoluminal, flow-disrupting device for treatment of saccular aneurysms. Stroke 2007;38:2346-2352

36. Becske T, Brinjikji W, Potts MB, Kallmes DF, Shapiro M, Moran CJ, et al. Long-term clinical and angiographic outcomes following Pipeline embolization device treatment of complex internal carotid artery aneurysms: five-year results of the Pipeline for uncoilable or failed aneurysms trial. Neurosurgery 2017;80:40-48

37. Imamura H, Sakai N, Sakai C, Fujinaka T, Ishii A; JR-NET Investigators. Endovascular treatment of aneurysmal subarachnoid hemorrhage in Japanese Registry of Neuroendovascular Therapy (JR-NET) 1 and 2. Neurol Med Chir (Tokyo) 2014;54:81-90 